\title{
Monteggia Bilateral Fracture: A Case Study
}

\author{
Louis Traore*, Moussa Sidibe, Abdoulkadri Moussa, Tieman Coulybali \\ Rabat Faculty of Medicine and Pharmacy Orthopedic Trauma, Mohammed V University, Rabat, Morocco \\ Email: *trlouis01@yahoo.fr
}

How to cite this paper: Traore, L., Sidibe, M., Moussa, A. and Coulybali, T. (2019) Monteggia Bilateral Fracture: A Case Study. Surgical Science, 10, 297-301. https://doi.org/10.4236/ss.2019.108032

Received: June 19, 2019

Accepted: August 23, 2019

Published: August 26, 2019

Copyright (c) 2019 by author(s) and Scientific Research Publishing Inc. This work is licensed under the Creative Commons Attribution International License (CC BY 4.0).

http://creativecommons.org/licenses/by/4.0/

\begin{abstract}
The authors report a rare case of Monteggia bilateral fracture combining bifocal fracture of the left ulna to a mid-shaft fracture of the radius with dislocation of the radial head and on the right; a fractured ulna with dislocation of the radial head occurring in a patient of 31 years after an accident of the public highway. In emergency, the treatment consisted of a fixation with radius special plates and a left pin ulnar upper radio. The evolution was marked by a good consolidation and after six months the patient had resumed operations.
\end{abstract}

\section{Keywords}

Fracture, Monteggia, Bilateral

\section{Introduction}

Monteggia fractures are bone fractures of the forearm on the ulnar or ulna with dislocation of the radial head. These fractures have been described for the first time by Giovanni Battista Monteggia in 1814 [1]. They are more common in children but are rare in adults and are only $1 \%$ to $2 \%$ of fractures of the upper limb. To our knowledge, bilateral form seems very little reported in literature.

We report a bilateral Monteggia variant combining bifocal fracture of the left ulna to a mid-shaft fracture of the radius with dislocation of the radial head and on the right; a fractured ulna with dislocation of the radial head occurring in a patient of 31 years after an accident of the public highway.

This lesion association is not so far described in the literature. That's why its clinical, paraclinical, therapeutic characteristics and its evolution should be discussed.

\section{Patient and Observation}

This is a 31-year-old patient brought by ambulance to the Emergency Ibn Sina Hospital following a highway accident. On admission, the patient was aware of good condition with traumatized attitude of upper limb, no skin opening. Ex- 
quisite pain on palpation (Eva 9) hemodynamically stable, no nerve deficit.

Radiography face of the left forearm is a bifocal fracture of the ulna and a fracture single mid-diaphysis of the radius associated with a dislocation of the radial head type 4 Bado (Figure 1). And on the right, the radiography of the right forearm fracture is a single medio-diaphyseal ulna associated with a dislocation of the radial head type 1 Bado (Figure 1).

The patient was taken under general anesthesia block withers to the upper limb root for osteosynthesis of the left ulna by two special plates radius followed by an osteosynthesis of the left radius by a special plate radius instability of the joint radio ulnar upper left was fixed by a pin (Figure 2) and on the right, internal fixation of the ulna by special plate radius (Figure 3).

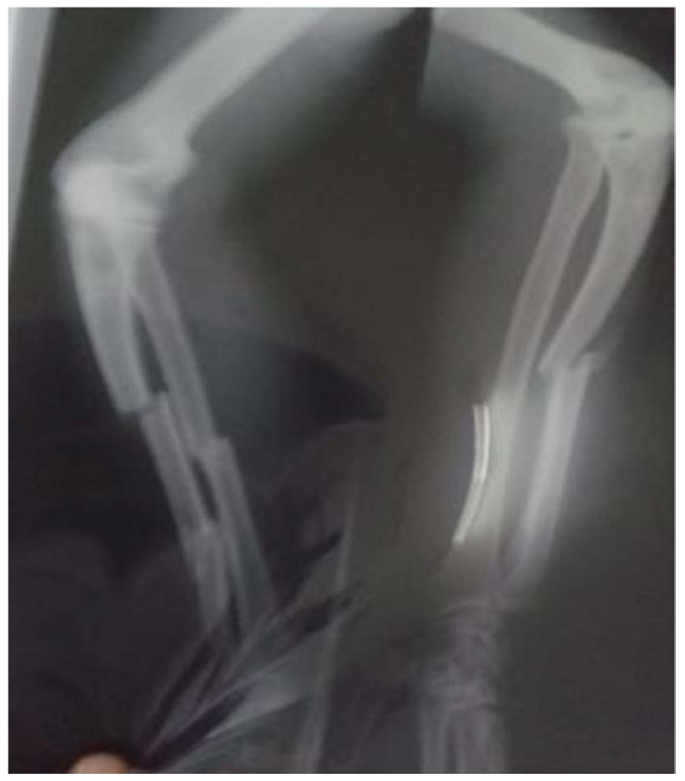

Figure 1. Face radiograph and Monteggia bilateral fracture.

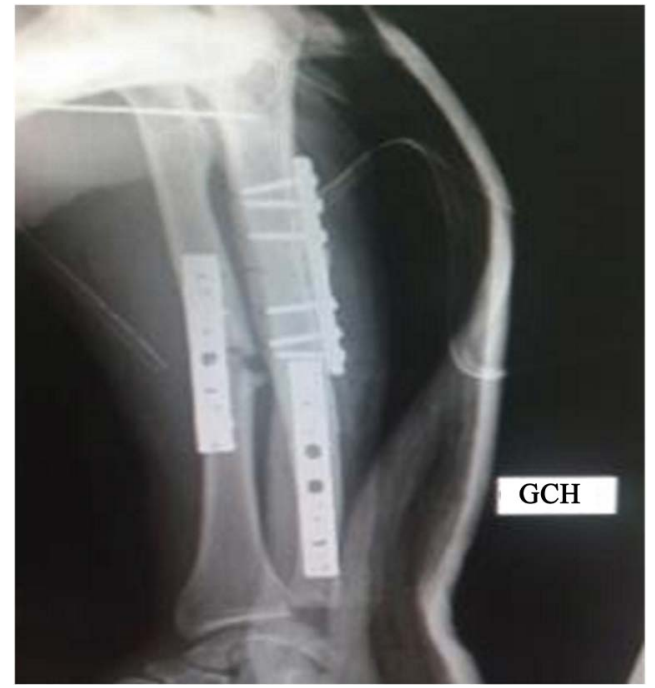

Figure 2. Left osteosynthesis by two radius special plates and the dislocation stabilization of the radial head with a pin proximal ulnar radio for the ulna and radius at the plate level. 
Removal of the pin was made to $\mathrm{J}+45$ followed by rehabilitation. At 6 months of motion of the left wrist was: The extension flexion respectively $75^{\circ}$ and $70^{\circ}, 65^{\circ}$ pronation and supination $70^{\circ}$ and left elbow flexion was $120^{\circ}$ and the extension at $-5^{\circ}$. On the right, the wrist flexion was $70^{\circ}$ and extension $75^{\circ}$ pronation $70^{\circ}$ and supination $75^{\circ}$ and at the elbow level, flexion $130^{\circ}$ and extension $0^{\circ}$. After 6 months, the consolidation has been good and the patient resumed operations.

\section{Discussion}

Monteggia fractures are rare. (1\% to $2 \%$ of fractures of the upper limb in man) [2] occuring during a high-energy direct impact on the forced supine member while in children and the elderly osteoporotic, they occur at low energy.

In our case on the left where we found a bifocal fracture of the ulna associated with a fracture of the radius and a dislocation of the radial head is the type 4 bado while on the right, it is type 1 given the complexity of the lesions, the treatment consisted of: on the left, the osteosynthesis by two plates for the ulna and a radius plate. Despite this treatment, it persisted a higher radio ulnar instability fixed by a pin (Figure 2) while other authors preferred a repair of the annular ligament [3]. On the Right, after ulna osteosynthesis, the stability of the radial head was retained (Figure 3 ) having regard to the complex lesions in some forms of Monteggia fracture, their treatments remain a challenge for the orthopedist.

Fractures conventional repair techniques can be used for the ulna: using plate and screws or intramedullary nailing with or without strapping seem most used.

In our case, we opted for the special plate osteosynthesis radius which would seem to give good results with good anatomical reduction and stable fixation (Figure 4).

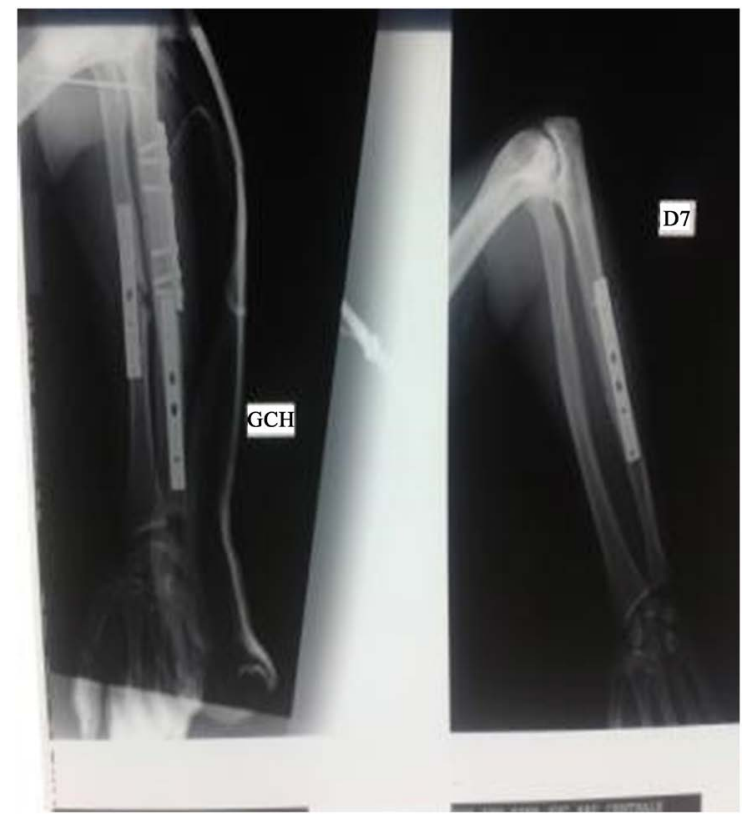

Figure 3. Osteosynthesis of two upper members. 


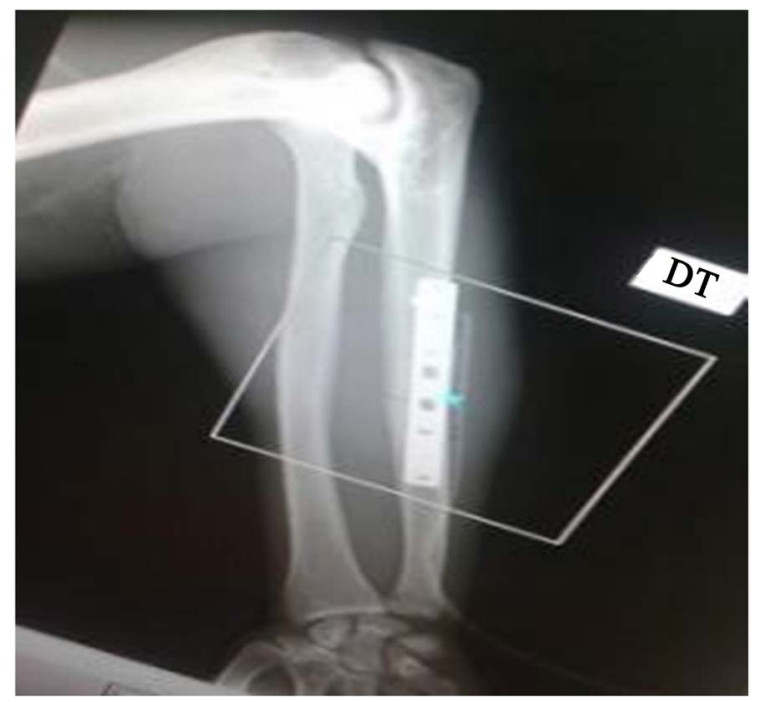

Figure 4. Osteosynthesis of the ulna by special radius plate.

Our results are closed to that of Kose. A in the ulna and Radius [4].

Regarding the radio-ulnar stabilization, it is possible to achieve a suture of the annular ligament or to replace it with a synthetic prosthesis. Another alternative is to transfix the radius and ulna by a screw or possibly a spindle [5] [6]. Each of the two techniques has its advantages and disadvantages: the screwed stabilization provides better compression with a reduced risk of instability [7]. Schwarz and Schrader report 32\% relaxation of the radial head after suturing of the annular ligament [8].

But it removes the possibility of pronation and supination of the forearm by suppression of relative movements between the radius and the ulna. The functional prognosis remains reserved in adults while in children, it is better [9] [10] despite surgical treatment. Schwarz and Schrader record 56\% residual instability, in our case the prognosis was good because pronosupination was respectively.

\section{Conclusion}

The Monteggia bilateral fractures are rare lesions in the adult. They occur following a high-energy trauma by direct or indirect impact on the forearm. Whose surgical care in emergency by a stable plate fixation provides good consolidation after 6 months.

\section{Contributions of Authors}

All authors have read and approved the final version of this manuscript.

\section{Conflicts of Interest}

The authors declare no conflicts of interest regarding the publication of this paper.

\section{References}

[1] Ristić, D., Jovanović, N., Cvetković, V., Stanković, B. and Vracević, B. (2011) 
Bilateral Monteggia Fracture in Adults. Vojnosanitetski Pregled, 68, 363-365. https://doi.org/10.2298/VSP1104363R

[2] Bado, J.L. (1967) The Monteggia Lesion. Clinical Orthopaedics and Related Research, 50, 71-86. https://doi.org/10.1097/00003086-196701000-00008

[3] Konrad, G.G., Kundel, K., Kreuz, P.C., Obrest, M. and Sudkamp, N.P. (2007) Monteggia Fractures in Adults: Long-Term Results and Prognostic Factors. The Journal of Bone and Joint Surgery. British Volume, 89, 354-360. https://doi.org/10.1302/0301-620X.89B3.18199

[4] Köse, A., Aydın, A., Ezirmik, N., Can, C.E., Topal, M. and Tipi, T. (2014) Alternative Treatment of Forearm Double Fractures: New Design Intramedullary Nail. Archives of Orthopaedic and Trauma Surgery, 134, 1387-1396. https://doi.org/10.1007/s00402-014-2058-9

[5] Evans, E.M. (1949) Pronation Injuries of the Forearm with Special Reference to the Anterior Monteggia Fracture. The Journal of Bone and Joint Surgery, 31, 578. https://doi.org/10.1302/0301-620X.31B4.578

[6] Harrington, I.J., Sekyi-Otu, A., Barrington, T.W., Evans, D.C. and Tuli, V. (2001) The Functional Outcome with Metallic Radial Head Implants in the Treatment of Unstable Elbow Fractures: A Long-Term Review. The Journal of Trauma, 50, 46-52. https://doi.org/10.1097/00005373-200101000-00009

[7] Kloen, P., Rubel, I.F., Farley, T.D., Weiland, A.J. and Helfet, D.L. (2003) Bilateral Monteggia Fractures. American Journal of Orthopedics, 32, 98-100.

https://doi.org/10.1007/s00132-002-0424-8

[8] Schwarz, P.D. and Schrader, S.C. (1984) Ulnar Fracture and Dislocation of the Proximal Radial Epiphysis (Monteggia Lesion) in the Dog and Cat: A Review of 28 Cases. Journal of the American Veterinary Medical Association, 185, 190-194.

[9] Beutel, B.G. (2012) Monteggia Fractures in Pediatric and Adult Populations. Orthopedics, 35, 138-144. https://doi.org/10.3928/01477447-20120123-32

[10] Singh, A.P., Dhammi, I.K., Jain, A.K., Raman, R. and Modi, P. (2011) Monteggia Fracture Dislocation Equivalents-Analysis of Eighteen Cases Treated by Open Reduction and Internal Fixation. Chinese Journal of Traumatology, 14, 221-226. 